Original Research Paper

\title{
Theoretical Analysis and Technical Seismicity Effect Assessment onto the Production Factory due to Traffic in Prešov City
}

\author{
Daniel Papán, Katarína Krkošková and Zuzana Papánová \\ Department of Structural Mechanics and Applied Mathematics, \\ Faculty of Civil Engineering, University of Žilina, Žilina, Slovakia
}

Article history

Received: 05-09-2017

Revised: 23-09-2017

Accepted: 23-11-2017

Corresponding Author:

Katarína Krkošková,

Department of Structural

Mechanics and Applied

Mathematics,

University of Žilina,

Faculty of Civil Engineering,

Žilina, Slovakia

Email: katarina.krkoskova@fstav.uniza.sk

\begin{abstract}
The technical seismicity effect assessment caused by traffic is the aim of article. The highway structure, as the mine of vibration, includes common layers and also special materials with dumping properties. It is the geomesh reducing the crack creation caused by fatigue, the tension strength increase and excess settlement The stress concentration in the bitumen structure reduces and separates into reinforcement. the machines sensible to vibration will be located in the production factory and it means the vibration level estimation caused by future mine of vibration is needed. The dynamic bedrock diagnostics was needed to provide for prognosis numerical model of dynamic effect ground half-space and dynamic effect future highway in the location of Prešov-Haniska and the dynamic interaction of this mechanism (the ground - pavement base structure). The dynamic diagnostics of bedrock main aim was determination of base dynamic parameters due to wave method coming out from surface wave stress spreading analysis in the real area and frequency characteristics of this bedrock area, frequency progression characteristics. The series of Impulse Seismic Method (ISM) measuring was done for named dynamic parameters determination in this bedrock that was modelled also with determined bedrock dynamic parameters in Visual FEA software, whereby the investigating area was separated into the parts according to the geological profile. The FEM model was created as a circle part plane. Dynamic load was applied as kinematic exciting as point vibration velocity and point vibration acceleration in the middle of the model surface. Measured pavement vibration values induced by the vehicle crossing on highways were the outputs. The distances which the mine vibration cross into and the standard limits that mustn't be over crossed during the production factory Spinea construction and its operation process are the results.
\end{abstract}

Keywords: Technical seismicity, FEM model, Dynamic parameters

\section{Introduction}

The aim of article is to determine the technical seismicity effect caused by traffic. The case study of investigation is production factory in Prešov City in Slovak Republic. There is no way how estimate the distance between the mine of vibration and the structure that is dangerous for this structure. Technical seismicity and its effects are knew in common as indisposed effect for structures and humans and they are caused by road traffic, rail traffic, construction or by blasting process (Surface Characteristic, 1987; Hanazato et al., 1991). Therefore the effects are needed to be analysed and determine the technical seismicity effect on the structure. Analyzed values comparable with all safety standard criteria must be kept with STN EN 1998-1, valid for Slovak Republic (JUHÁSOVÁ, 1985; 1987; STN EN 1998-1).

\section{Materials and Methods}

The mine of vibration is highway D1 Prešov ZápadJuh. Its pavement has got common layer structure, whereby the reinforcement elements are in road base. These have vary functions, e.g. better stress spreading during nonuniform settlement, reducing the risk of crack creating and it means that these elements have the dumping properties.

The geomesh strength is $50-200 \mathrm{kPa}$. The dynamic diagnostics of the bedrock, it means determination of 
basic dynamic parameters in the locality due to wave method basis coming out from the strength surface wave spreading analysis, was needed to complete to analyse vibration effect spreading cross the bedrock mass area on the future factory. From first of all, it is surface and shear wave strength velocity measuring, dumping parameters and seismic elastic modulus according with them, OR complex dynamic elastic modules. Frequency characteristics are another important factors of the bedrock area, so called frequency transmission characteristics, OR their modules. Determined transmission characteristics allow to define the frequency band, which the traffic vibration can easily transmit to the structure due to resonance effects.

In regard of following aims, the Impulse-Seismic Method (ISM) was applied, in which the spreading surface waves strength process in the form of impulses from the mine of impulses is observing. The force impulse is creating by impulse machine (light dynamic slab) by falling mass onto the contact circle slab located on the half-space surface. In application of ISM, the shear or surface (Rayleigh) wave velocity between two accelerometers, which are localized with some distance on the half-space surface. Except of the surface wave velocity, the surface wave strength dumping and the bedrock transmit characteristic is able to determine at the IS Method.

\section{Dynamic Parameters of the Bedrock Area}

The IS Method measure series were provided for named bedrock dynamic parameters determination in the locality. The impulse machine location and the measured point's location, where located accelerometers as during the locality dynamic response measuring in, is schematically shown in Fig. 1. The velocity of surface wave was measured between points B1 and B2.
In the point of level vibration intensity set during the blasting process in the locality, there was needed to detect basic dynamic parameters of the locality. Following mechanical characteristics were included into the bedrock elasticity modulus calculation:

- $\mu \approx 0,33$ (Poisson coefficient)

- Volume mass $\rho_{13} \approx 1760 \mathrm{~kg} / \mathrm{m}^{3}$ (for clay, gravel, point B1 - B2),

- Volume mass $\rho_{13} \approx 2600 \mathrm{~kg} / \mathrm{m}^{3}$ (for the bedrock)

The impulses time history $v_{1}(t)$ and $v_{2}(t)$ and their equivalent power spectrum $G_{i i}(f)$, cross power spectrums $G_{i k}(f)$, coherence functions $\gamma_{34}^{2}(\mathrm{f})$ and transmit characteristics are shown in the Fig. 2. In the basis of provided correlation analysis-cross correlation function $R_{i k}(\tau)$, the Rayleigh surface wave velocity spreading was detected:

- For clay, soil and gravels (point B1 - B2 compressed bedrock in area of $0,0-2,5 \mathrm{~m}$ under the surface $\mathrm{C}_{\mathrm{R}} \approx 92-98 \mathrm{~m} / \mathrm{s}$, (Impulses)

- For the bedrock (point B2 - B3 the foundation soil) on the level of $2,5-5,0 \mathrm{~m}$ under the surface $C_{R} \approx 128-132 \mathrm{~m} / \mathrm{s}$, (Impulses)

In the basis of theoretical analysis and table values from geological profiles, the dependence of Rayleigh and shear wave velocity can be detected (Makovička, Jr. 2009; WOLF, 1985)., the formulas valid:

$$
C_{S}=\frac{C_{R}}{0,93} \quad[m / s]
$$

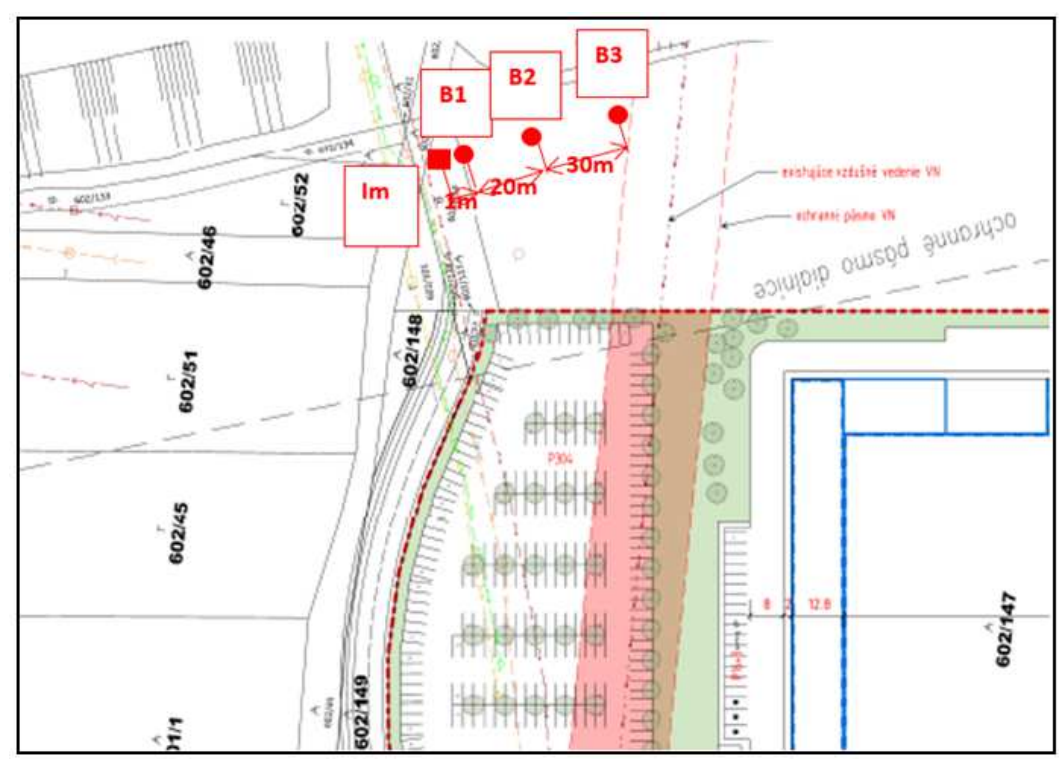

Fig. 1: The experimental measuring scheme (ISM) 
Daniel Papán et al. / International Journal of Structural Glass and Advanced Materials Research 2017, 1 (2): 24.31 DOI: 10.3844/sgamrsp.2017.24.31

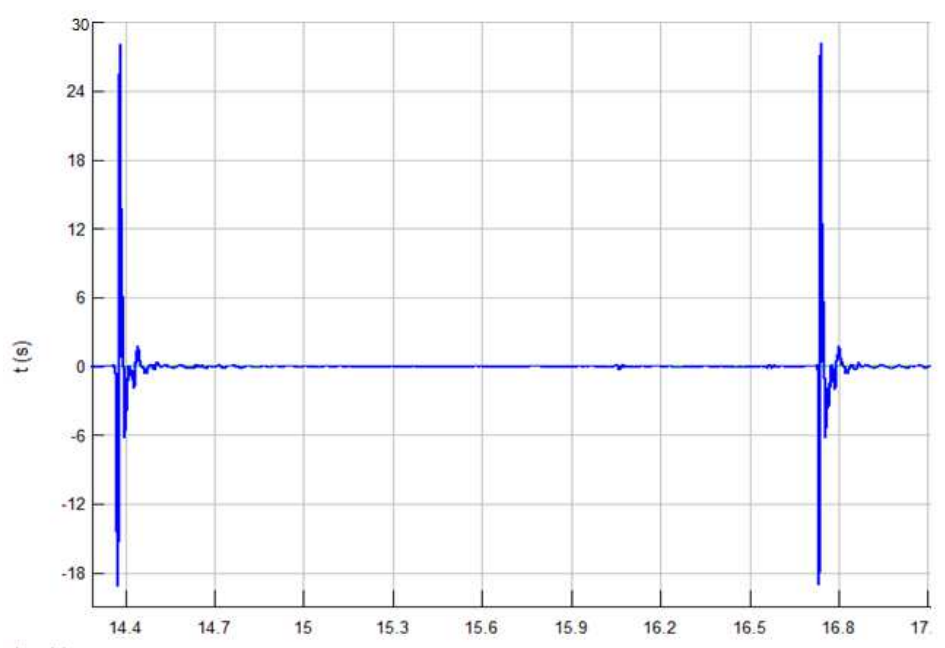

$(\mathrm{mm} / \mathrm{s})$

Time history v1(t); Point-B1 M no.2 - 2 x Impulse; vRMS = 1,115 mm.s-1

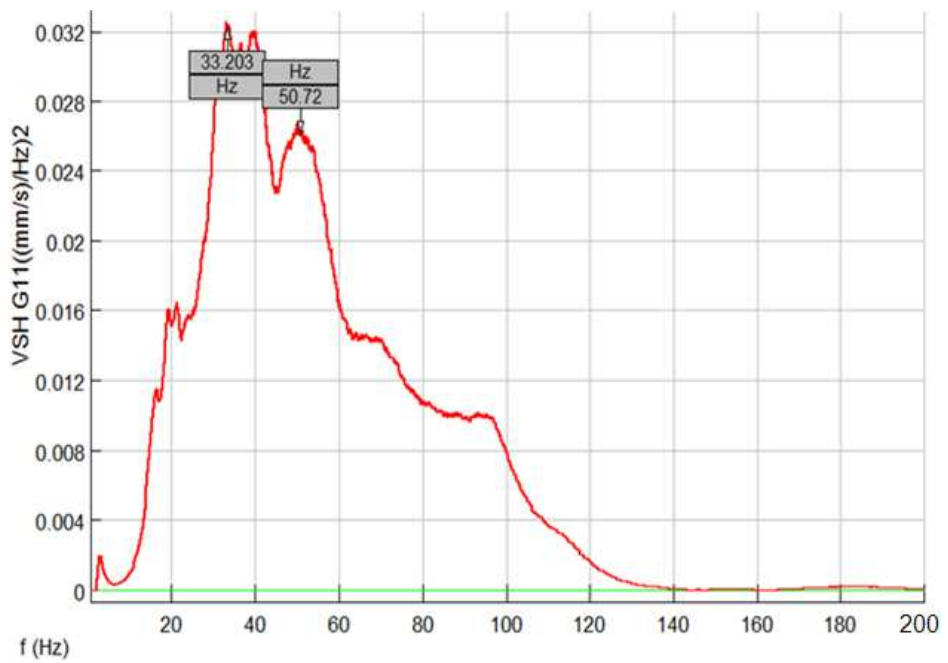

PSD G11 (f); Point - B1 Measuring. 2 - 2 x Impulse

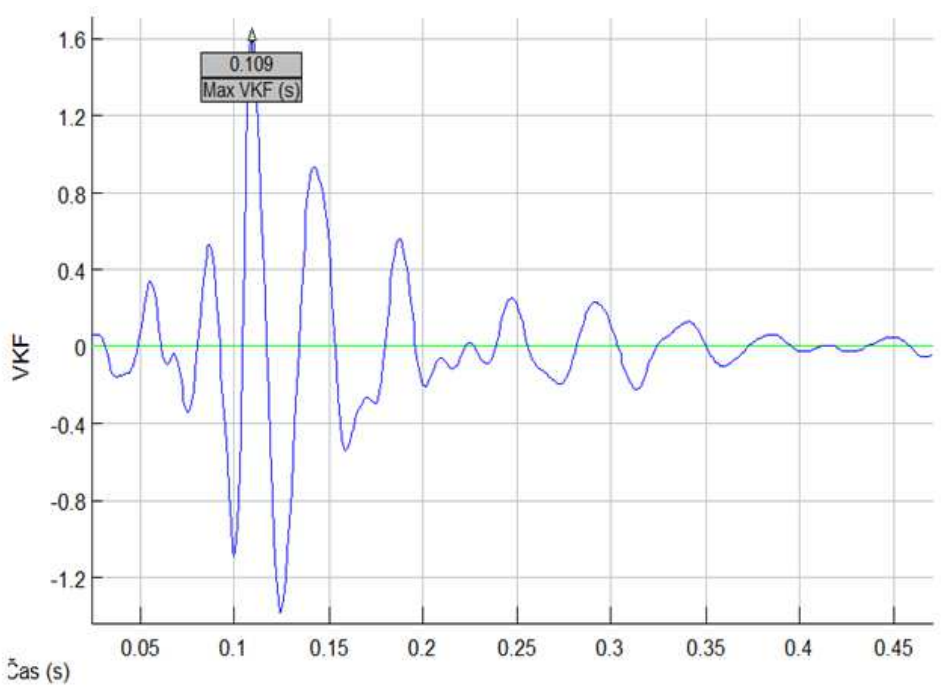

Cross Correl. Fun. R13(f): Points - B1/B2 M no.2 - 


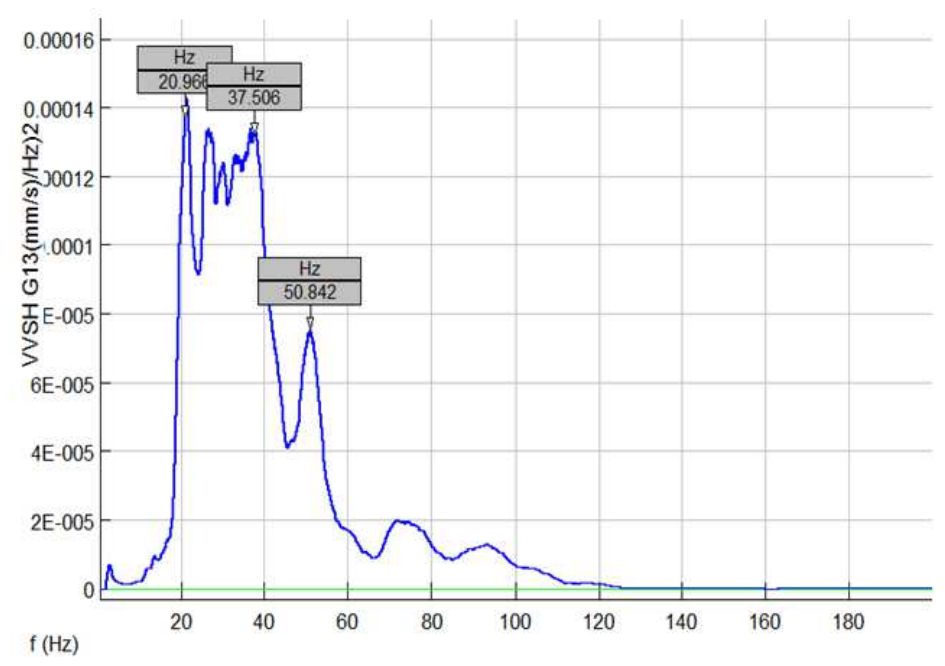

Cross PSD G13 (f); Point-B1/B2 M no.2- 2 x Impulse

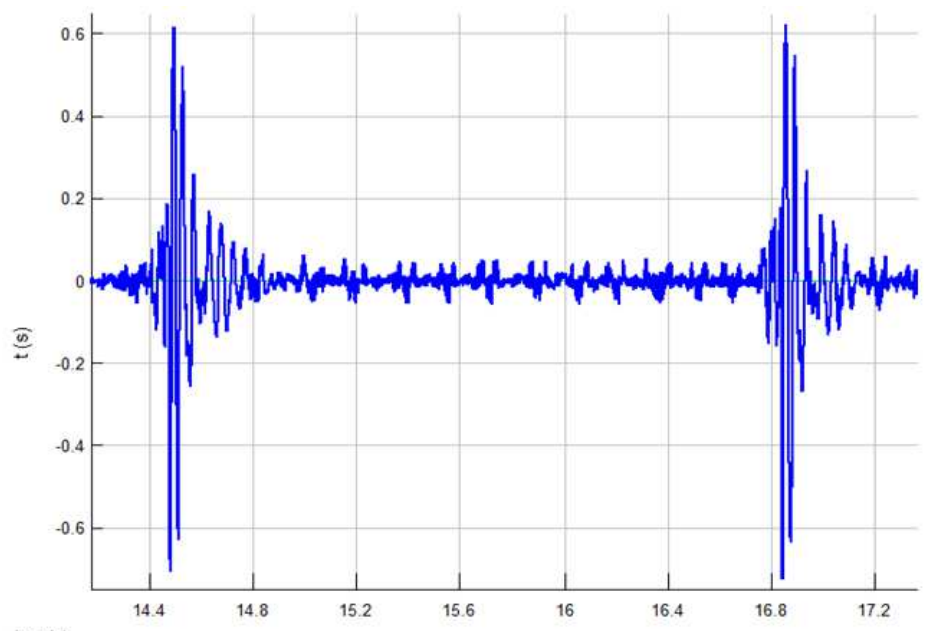

$(\mathrm{mm} / \mathrm{s})$

Time history v3(t); Point - B2

Measuring no. $2-2 \times$ Impulse; $v R M S=0,061 \mathrm{~mm} . \mathrm{s}-1$

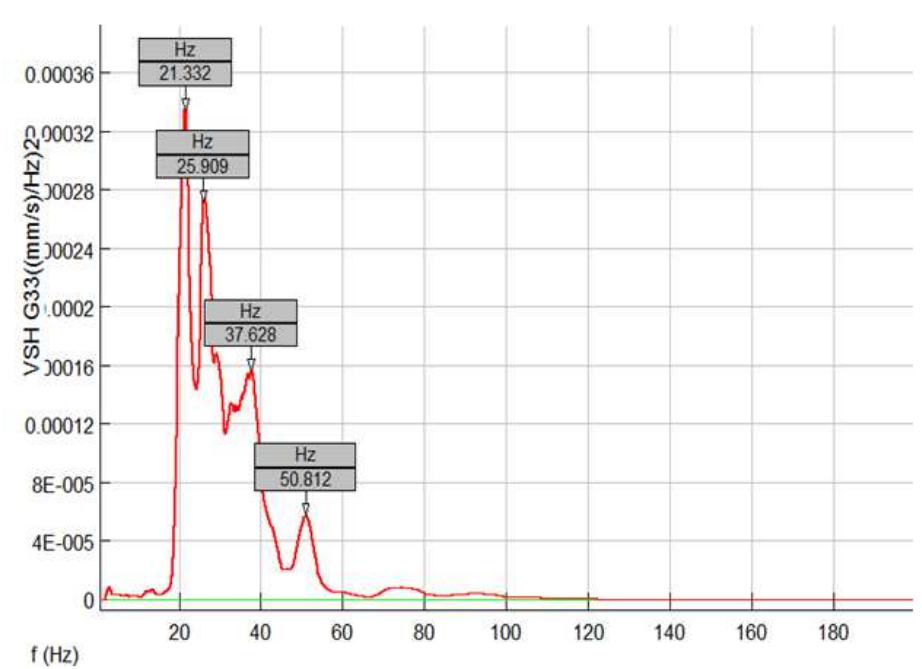

PSD G33 (f); Point - B2 Measuring no.2 - 2 x Impulse 


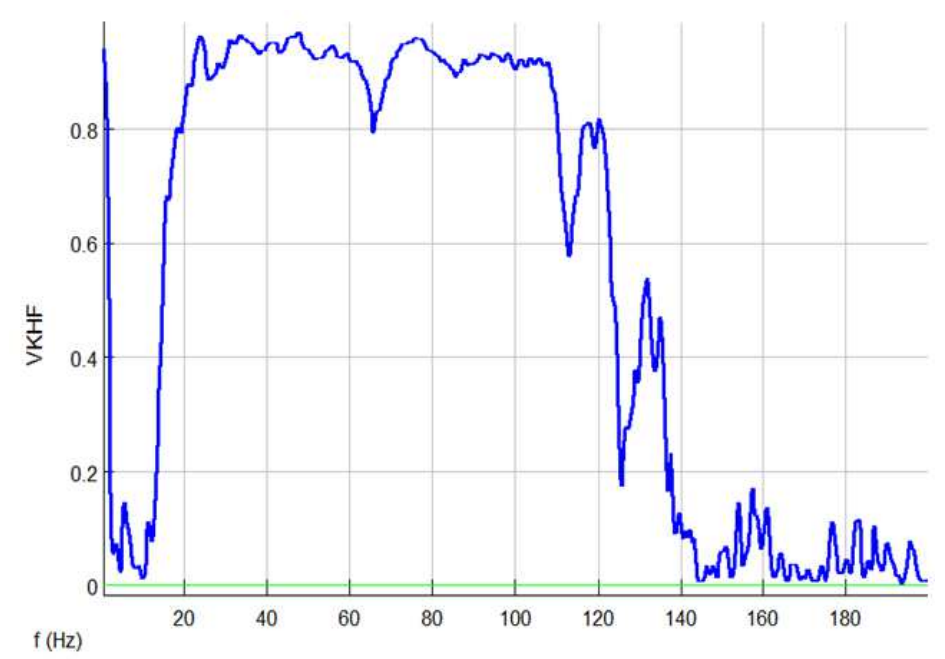

Coher. Function, Points-B1/B2 M no. 2 - 2 x Impulse

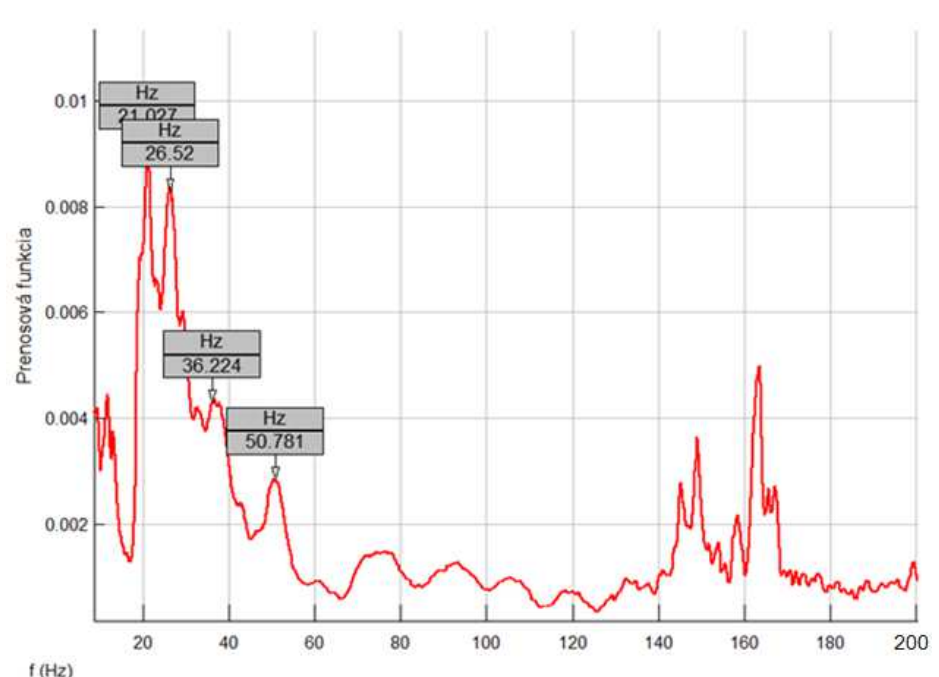

Transmission function H13 (f); Point-B1/B3 M no.2 - 2Impulse

Fig. 2: ISM - impulse analysis of points B1,B2, B3

Seismic shear elasticity modulus can be calculated from formula:

$$
G_{0}=C_{\check{s}}^{2} \rho,[M P a]
$$

where $\rho$ - volume mass $\left[\mathrm{kg} / \mathrm{m}^{3}\right]$.

Seismic modulus in the press and tensile can be calculated from formula :

$E_{0}=2 G_{0}(1+v)$

Modified formula for E0 calculation kept with bedrock parameter equals:

$$
E_{0}=3,142 \cdot 10^{-7} C_{R}^{2} \rho \quad[M P a]
$$

After the parameters' average value substitution, the elasticity modulus value equals for:

$$
\begin{gathered}
\text { Bedrock }\left(\rho_{13}=2600 \mathrm{~kg} / \mathrm{m}^{3}\right) \\
E_{0} \approx 77,33[M P a], G_{0} \approx 29,74[M P a],
\end{gathered}
$$

Foundation soil (point B1 - B2, $\rho_{34}=1760 \mathrm{~kg} / \mathrm{m}^{3}$ ):

$$
E_{0} \approx 39,42[M P a], G_{0} \approx 14,40[M P a]
$$

Dumping parameter $\boldsymbol{\alpha}_{R}$ including material and geometrical area dumping for entire frequency band $(0-$ $100 \mathrm{~Hz}$ ), was calculated from formula:

$$
\alpha_{R}=-\left(l_{0}-l_{x}\right)^{-1} \ln \left(k \sigma_{d}^{0} / \sigma_{d}^{x}\right)
$$


where, $\sigma_{\mathrm{d}}^{0}, \sigma_{\mathrm{d}}^{\mathrm{x}}$ are effective velocity vibration amplitude values (rms) in the distances $l_{0}, l_{x}$ from the mine of vibration, which are detected from power spectral densities $G_{i i}(f)$ and the geometrical dumping coefficient Melcer (2000; 2016; Stachova, 2004) :

$$
k=\left(l_{0} / l_{x}\right)^{\frac{1}{2}}
$$

In this locality, the dumping parameter $\alpha_{R}$ had following average values during the vibration bedrock exciting by impulse (measuring from series no. 1 and 2):

$$
\alpha_{R} \approx 0,0226 \mathrm{~m}^{-1}
$$

If the place character of the vector's surface waves spreading, then the dumping parameter value can be calculated and that in the basis of rotating surface wave vector's vertical part measuring $v_{i}(t)$.

The frequency transmission, characterized by cross power spectral density $G_{i k}(f)$ or transmission function $H_{i}(f)$, can be determined by impulse exciting as best solution, whereas this process is not loaded by exciting frequencies wide spectrum from the vehicles crossing. It can be said that the bedrock has got expressive frequency band of the vibration transmission:

$$
f_{D I}=20 \div 50 \mathrm{~Hz}
$$

Stabilized point B3 is shown in the Fig. 3 from the measuring process IS Method in the locality of Haniska - Prešov.

\section{FEM Bedrock Model Response Calculation}

Geometric parameters of model were detected in the basis of the locality space layout. Investigated area was separated into parts according to the geological profile. Material parameters were set for IS Method values in situ.

FEM model of the bedrock was created in the software of VisualFEA as plane model with the circle part shape. The length of surface edge is $100 \mathrm{~m}$ and the depth is non-constant from $0 \mathrm{~m}-40 \mathrm{~m}$. Material coefficients used in the model are elasticity modulus $\mathrm{E}=$ $40 \mathrm{MPa}$, Poisson coefficient $\mu=0,33$ and volume gravity $\gamma=1600 \mathrm{~kg} / \mathrm{m}^{3}$ for surface layer, dumping parameters were set for both layers due to IS Method results. The boundary conditions of the bedrock space model were set as rigid bearing along the circuit curved edge side.

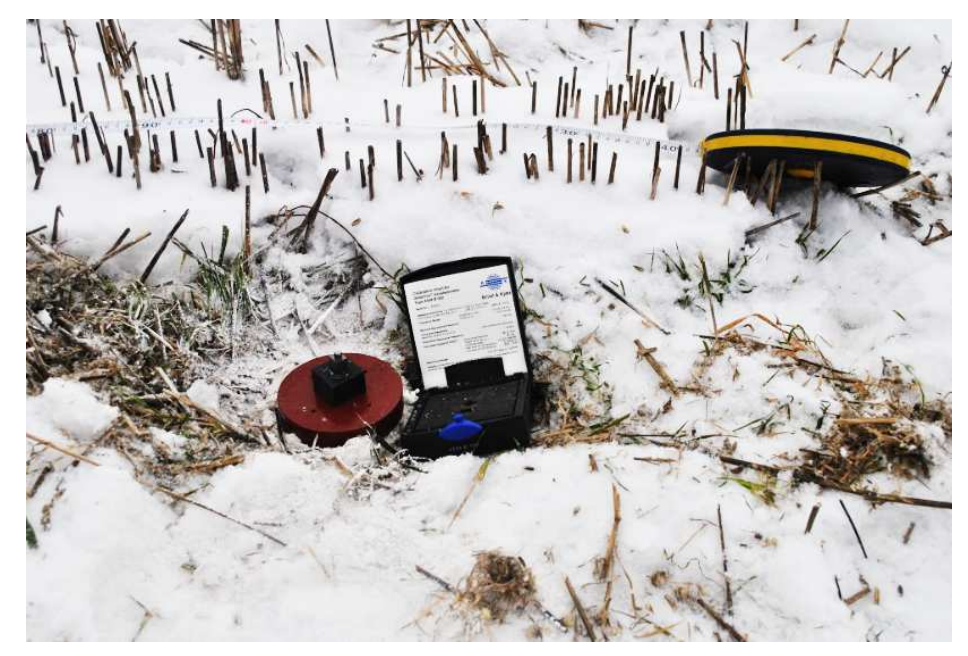

Fig. 3: Measured point B2 - Prešov - Haniska

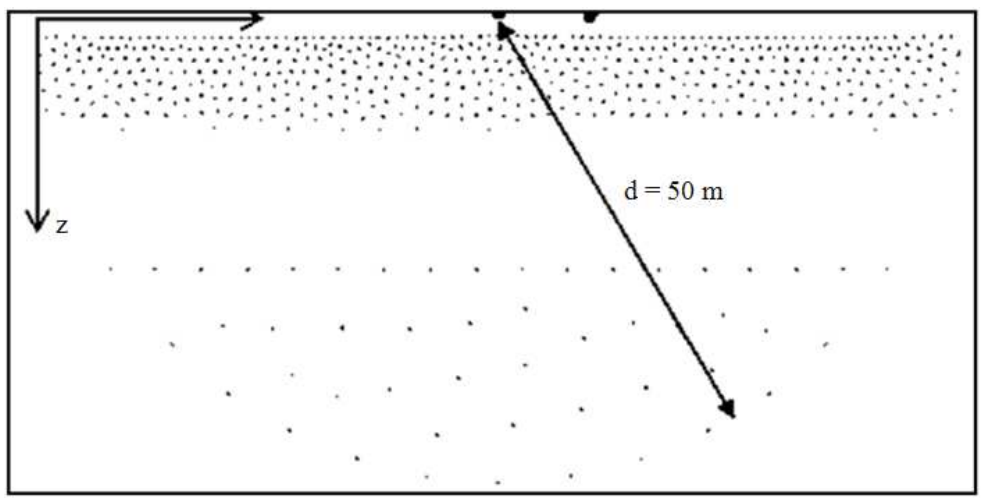

Fig. 4: FEM model of the bedrock 


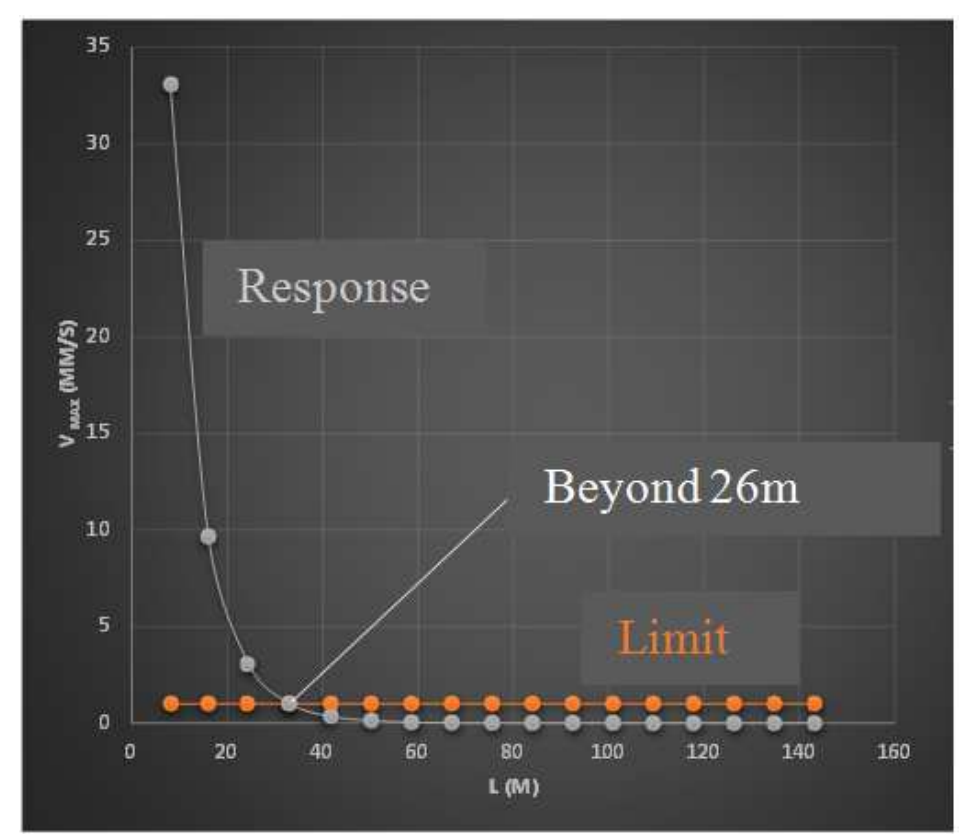

Fig. 5: The parametrized FEM dynamic calculations results of elastic bedrock area in the form of $v_{R M S}-$ vibration response of the landscape surface in the distance of 140m (highway traffic)

FEM solution leads to the system of algebraic formulas for 2772 plane triangular elements got together with 1377 points of mesh separating. Meshing was symmetrical and condensed to the surface and to the symmetrical line (Fig. 4).

\section{Dynamic Load}

Dynamic load was applied onto the FEM model in the middle of the surface as kinematic exciting in the form of point vibration velocity and in the form of point vibration acceleration. Pavement vibration measured values from the vehicles crossing $n$ highways were the outputs.

\section{Results}

The diagram dependency of comparing standard values and distance is the dynamic calculation result on this parametric model (Fig. 5). This result leads to conclusions and recommendations for realization and reductions for the structures.

From the point of significance, the future building of production factory belongs to category I and it means that the limit value of vibration level kept with STN EN 1998-1, which is not safe for structure yet and which mustn't be exceeded is:

$$
v_{\text {rms }, \max }=1,5 \mathrm{~mm} / \mathrm{s}
$$

On the base of our advance research, the supposition is that the reinforcement pavement layers are dumping and reducing the vibration spreading through the bedrock that is on the way to the structure.

\section{Conclusion}

The aim of this article was to determine the technical seismicity effect caused by road traffic on to the future structure production factory in the city of Prešov. The mine of vibration is highway D1 Prešov Západ-Juh. The pavement structure is reinforced with special geomesh filled with geotextile, which have also dumping effect. Designed distance between factory and highway is $100 \mathrm{~m}$. The dynamic and frequency bedrock parameters, detected by dynamic diagnostics, were used as input values into the FEM model. The surface vibration response shown that the factory structure will be exposed to vibration from traffic if the factory is built from highway in the distance of $26 \mathrm{~m}$.

\section{Acknowledgement}

Thanks to the University of Žilina, Faculty of Civil Engineering, Department of Structural Mechanics and Applied Mathematics for support in making this article.

\section{Funding Information}

This paper was financed from the Faculty of Civil Engineering budget.

\section{Author's Contributions}

Each author participated on writing this article by equal work. 


\section{Ethics}

This article is original, no issues from this article were copied without citation.

\section{References}

Hanazato, T., K. Ugai, M. Mori and R. Sakaguchi, 1991. Three-dimensional analysis of induced trafficvibrations. J. Geotech. Eng., 117: 1133-1151. http://ascelibrary.org/doi/abs/10.1061/(ASCE)07339410(1991)117:8(1133)

JUHÁSOVÁ, 1985. Pôsobenie seizmických pohybov na stavebné konštrukcie. (eng.: Seismic movements effecting on structures) Veda, Bratislava, 1985

JUHÁSOVÁ, 1987. Diagnostika dynamických vlastností konštrukcií. (eng.: Dynamic structure properties diagnostics), USTARCH - SAV, Bratislava.

Makovička, Jr. M., 2009. Response analysis and vibroinsulation of buildings subject to technical seismicity. Great Britain: Wit Press, ISBN: 978-1-84564-180-1, pp: 104.
Melcer, 2016. The dynamic analyses solutions in frequency band. In: Dynamics of Civil Structures: Chapter 5. University of Žilina, pp: 76-126.

Melcer, K., 2000. Dynamic of structures. Žilina: University of Žilina.

Stachova, M., 2004. Dynamic Impact modelling of traffic vehicles effecting on structures. Košice

STN EN 1998-1, 2005. STN 730036 Eurocode 8: Navrhovanie konštrukcií na seizmickú odolnost'. (eng.: Seismic Resistance Structure Design). Bratislava. SÚTN, ICS 91.120.25 (NNR), pp: 166.

Surface Characteristic, 1987. Technical report No. 1. XVIIIth World Road Congress, Brussels.

WOLF, 1985. Dynamic Soil Structure Interaction, Prentice Hall, Inc., Engelwood Cliffs, New Jersey. 